\title{
Review
}

Pharmacology

\section{Statins in Asthma: A Closer Look into the Pharmacological Mechanism of Action}

\author{
Nour A. Al-Sawalha ${ }^{a}$ Brian J. Knoll ${ }^{\mathrm{b}}$ \\ ${ }^{a}$ College of Pharmacy, Jordan University of Science and Technology, Irbid, Jordan; ${ }^{b}$ College of Pharmacy, \\ University of Houston, Houston, Tex., USA
}

\section{Key Words}

Asthma $\cdot$ Statins $\cdot 3-H y d r o x y-3-m e t h y l-g l u t a r y l-C o A$ reductase inhibitors - Isoprenylation - Animal model of asthma · Subepithelial fibrosis · Eosinophils

\begin{abstract}
The effect of stains in asthma is mediated through targeting several signaling molecules that are involved in the development of asthma phenotype. In vitro and in vivo studies revealed that statins reduce airway smooth muscle cells proliferation and inflammatory mediators' release. Statins reduce chemokine release and mucus production from airway epithelial cells besides attenuating subepithelial fibrosis and eosinophils recruitment. In acute and chronic allergen driven animal models of asthma, statins reduce airway hyperresponsiveness, inflammation and remodeling. However, the effectiveness of statins in clinical trials results in contradictory conclusions based on study design and treatment protocol. Therefore, more clinical trials are needed to evaluate their role in asthma patients.

๑) 2016 S. Karger AG, Basel
\end{abstract}

\section{Introduction}

Asthma is a chronic airway inflammatory disorder [1, 2] that is characterized by airway hyper-responsiveness (AHR), airway obstruction, airway inflammation and mucus metaplasia. Worldwide, asthma affects 300 million people and the number is growing dramatically to reach 400 million by year $2025[3,4]$.

The inflammatory profile of asthma is characterized by an amplified T-helper- $2\left(\mathrm{~T}_{\mathrm{H}} 2\right)$ response at the expense of $\mathrm{T}_{\mathrm{H}} 1$. The elevated levels of $\mathrm{T}_{\mathrm{H}} 2$ cytokines (interleukin (IL)-4, IL-5 and IL-13) play a major role in orchestrating asthma inflammation and hence mediate airway remodeling [5].

Different inflammatory cells are recruited to the airways and participate in airway remodeling and disease progression. Asthma is characterized by eosinophilic type of inflammation [6]. Eosinophils release several granular proteins and cytokines that mediate epithelial damage and recruitment of further inflammatory cells, respectively [7]. $\beta_{2}$-Adrenoceptor ( $\beta_{2}$-AR) agonists and inhaled corticosteroids (ICSs) are the most commonly used medications that target bronchoconstriction and inflammation of asthma, respectively. ICSs, especially at high doses in severe persistent asthma, result in serious systemic side effects such as growth impairment in children [8] and reduction in bone density [9]. Chronic use of $\beta_{2}$-AR agonists is also associated with serious consequences such as increased risk of severe asthma exacerbations and possible death $[10,11]$. The fear of long-term side effects of ICS and $\beta_{2}$-AR agonists creates a subset of patients who have uncontrolled disease. Additionally, another subset of asthmatic patients, ( 5-10\%), are not responsive to conventional treatment approaches and exhibit severe

\section{KARGER}

E-Mail karger@karger.com www.karger.com/pha
(C) 2016 S. Karger AG, Basel

0031-7012/16/0986-0279\$39.50/0
Nour A. Al-Sawalha, PharmD, PhD

College of Pharmacy

Jordan University of Science and Technology

Irbid 22110 (Jordan)

E-Mail nasawalha@just.edu.jo 
disease manifestations [12]. Thus, more research is required to improve the pharmacological approaches in asthma treatment. Statins are among the investigated agents for the treatment of asthma.

\section{Statins}

Statins are the most commonly used anti-hyperlipidemic agents for decades. Statins inhibit 3-hydroxy3-methyl-glutaryl-CoA (HMG-CoA) reductase enzyme [13] and thus inhibit the conversion of HMG-CoA to L-mevalonic acid, a rate limiting step in cholesterol synthesis. Of note, the mevalonate pathway is involved in the formation of membrane-raft microdomains, which is essential for immune system signaling and localization of major histocompatibility complex class II [14] on antigen presenting cells [15].

Not only is the synthesis of cholesterol reduced by statins, but also the production of numerous isoprenoid metabolites such as geranylgeranyl pyrophosphate (GGPP) and farnesyl pyrophosphate (FPP) $[16,17]$. FPP and GGPP are involved in the process of protein prenylation which is an essential post-translational modification for several proteins such as Ras, Rab and protein kinases among others [18]. These modifications are essential for membrane association [19]. Knowing that isoprenylated proteins control several intracellular signaling and responses, it is expected that statins would have additional effects beside their lipid lowering mechanism.

\section{Pharmacological Targets of Statins in Asthma}

Both in vivo and in vitro evidence points toward the potential role of statins in attenuating the asthma phenotype. An elegant study conducted by Takeda et al. [20] showed normal human bronchial smooth muscle cells (SMCs) that were treated with simvastatin resulted in reduction of cell proliferation and DNA synthesis induced by fetal bovine serum. This inhibitory effect was due to inhibition of RhoA geranylgeranylation and not by inhibition of Ras farnesylation [20]. Increased airway SMC (ASMC) proliferation is a hallmark of asthma [21] and it has been found that there is increased proliferative capacity of cultured ASMCs from asthma patients as compared to ASMCs from healthy individuals [22]. Contraction of ASMCs results in airway narrowing in response to nonspecific stimuli or pharmacological ago- nists. Because of this, ASMCs are the predominant cell type studied for control of AHR.

Of interest, Rho plays a critical role in regulating ASMC contraction through its effect on myosin light chain (MLC), one of the major proteins that regulate muscle contraction. MLC is activated by MLC kinase (MLCK) and inactivated by MLC phosphatase (MLCP) resulting in smooth muscle contraction and relaxation, respectively [23]. Of interest, MLC is also phosphorylated by Rho kinase [24], a downstream signaling molecule of Rho [25]. Rho kinase phosphorylates ser-19 residue of MLC, which is same site phosphorylated by MLCK [24] and henceleads to smooth muscle contraction. Rho kinase also phosphorylates other proteins that are involved in smooth muscle contraction, such as CPI-17, that inhibits MLCP [26] and calponin [27]. Calponin is a specific protein of SMCs that is involved in regulating SMCs contraction [28].

ASMCs release inflammatory mediators $[22,29]$ and undergo hypertrophy and hyperplasia in the asthma patient's airways [30]. Several factors were found to be involved in ASMC proliferation including ILs (such as IL-6 and IL-1 $\beta$ ), growth factors (such as insulin-like growth factors) and contractile agents acting through a Ras/ERK/ phosphatidylinositol 3-kinase pathway [31]. Eicosanoid agents are also inducers of ASMC proliferation. It has been found that treating cultured human ASMCs with rosuvastatin inhibited cell growth, as measured by $\left[{ }^{3} \mathrm{H}\right]$ thymidine nuclear incorporation, in response to eicosanoid agents [32]. Of interest, it has been suggested that inhibition of both geranylgeranylated and farnesylated proteins are involved in the effect of rosuvastatin [32].

The role of airway epithelial cells, the second most predominant parenchymal lung cell, in asthma has been the subject of less intense investigation and initially considered primarily as mechanical barrier. However, several recent studies have shown an emerging role for epithelium as a tissue orchestrating a sophisticated set of responses. These include a critical role in initiating the immune response to inhaled allergens [33] and polarizing the response toward $\mathrm{T}_{\mathrm{H}} 2$ [34]. Moreover, airway epithelial cells, through producing mucus to form mucus plugs, cause airway obstruction. Mucous plugs, together with AHR, are the cause of death in almost all asthma-related fatalities [35]. Treating primary mouse tracheal epithelial cells with atorvastatin attenuated IL-13 induced expression of several chemokines such as eotaxin-1 (an eosinophil attractant) and chemokines MCP-1, MCP-2 and MCP-3 [36].

Statins affect mucus overproduction by airway epithelial cells. Simvastatin reduced the expression of the $M U C 5 A C$ gene, the main mucin-producing gene in gob- 
let cells $[37,38]$, in response to acrolein in cultured NCI$\mathrm{H} 292$ cells [39]. Oral administration of lovastatin attenuates Muc5ac expression in the allergen-driven murine model of asthma [40]. Rosuvastatin also reduced mucus metaplasia in the chronic murine model of asthma [41]. Of interest, rosuvastatin's effect is mediated through regulating the expression of gamma-aminobutyric acid type A receptor $\left(\mathrm{GABA}_{\mathrm{A}} \mathrm{R}\right)$ [41]. Mice lungs and human airway epithelial cell lines express $\mathrm{GABA}_{\mathrm{A}} \mathrm{R}$ [42]. The increased levels of IL-13, directly or mediated by allergen exposure, enhances the release of GABA and hence activation of $\mathrm{GABA}_{\mathrm{A}}$ Rs and results in chloride efflux and mucus overproduction that is observed in asthma [42].

Decreasing airway eosinophil recruitment is another proposed anti-inflammatory effect of statins. Fluvastatin and lovastatin inhibited the adhesion of human eosinophils to recombinant human intercellular adhesion molecule-1, and this effect was reversed by the addition of mevalonate [43]. In addition, pravastatin and fluvastatin reduced the expression of intercellular adhesion molecule- 1 and the release of TNF- $\alpha$, IFN- $\gamma$ and IL-12 from cultured human peripheral blood mononuclear cells [43]. In recent years, it has been suggested that the accumulation of eosinophils in asthma could be due to their prolonged survival and defective apoptosis [44, 45]. Hence, strategies to induce eosinophil apoptosis in asthma are an appealing area of research. Of interest, IL-13 and IL-5 are among the cytokines that inhibit eosinophil apoptosis [44]. Nuclear factor-kappa B (NF- $\kappa B)$ is a transcription factor that plays a major role in asthma pathogenesis [46, 47], and inhibition of the NF- $\kappa$ B signaling pathway enhances eosinophil apoptosis [48]. Simvastatin reduces the level of activated NF- $\mathrm{\kappa B}$ in inflammatory cells and lung tissues as well as airway eosinophils recruitment in ovalbumin (OVA) induced allergic airway inflammation [49].

Oral administration or intraperitoneal injection of simvastatin decreased the level of total inflammatory cells and eosinophils in chicken egg OVA-driven murine models of acute [50] and chronic asthma [51]. Additionally, simvastatin reduced bronchoalveolar lavage fluid levels of IL-4 and IL- 5 as well as the extent of inflammatory cell infiltration in the lungs [50]. It has been found that the effect of simvastatin on AHR and airway inflammation attenuation is through a mevalonate independent mechanism [52]. Several small $G$ proteins of Rho family, such as Rho, Rac1, Rac2, Ras and cdc42, were inactivated by simvastatin in lung tissues of mice that were sensitized and challenged with OVA [49]. Additionally, simvastatin inhibited the level of activated mitogen-activated protein kinases (MAPKs) - ERK, JNK and p38 - in inflammatory cells and

Pharmacology of Statins in Asthma lung tissues [49]. MAPKs play a major role in inflammation [53], asthma pathogenesis and airway remodeling [54].

Imamura et al. [55] found that pravastatin inhibited $\mathrm{T}_{\mathrm{H}} 2$ proliferation and the release of $\mathrm{T}_{\mathrm{H}} 2$ cytokines and IL-17 when administered during the sensitization period in allergen driven murine model of asthma. IL-17 is involved in mediating several asthma responses, such as secretion of mucus and accumulation of neutrophils [56].

Subepithelial fibrosis, important for airway remodeling, occurs due to the accumulation of extracellular matrix proteins and enhanced fibroblast-myofibroblast transition [57]. Fibronectin is among these extracellular matrix proteins [58] and it has been found that asthmatic human bronchial epithelial cells are intrinsically more capable of producing higher levels of fibronectin [59]. Of interest, fibronectin stimulates the proliferation of human bronchial epithelial cells and the release of inflammatory mediators from epithelium [59]. Treating primary human fibroblast cells from asthma patients with simvastatin and lovastatin reduced fibronectin release [60] and myofibroblast differentiation, respectively, in response to transforming growth factor beta 1 [61]. The inhibitory effect of lovastatin is mediated by decreasing the intracellular cholesterol content and not through suppression of prenylation or reactive oxygen species production [61]. The effect of simvastatin on early airway remodeling markers in an acute model of asthma was through inhibiting the expression of arginase-1 and arginase activity [62]. The increased level and activity of arginase in asthma result in reduction of the released nitric oxide, which has anti-inflammatory and bronchodilator effect, and L-ornithine [63].

\section{Clinical Evidence of the Role of Statins in Asthma}

The clinical role of statins in asthma has been the focus of several clinical studies for years and has resulted in contradictory findings. It has been found that simvastatin administration did not reduce airway resistance [64], blood eosinophil levels or improve lung function [65] in asthma patients with mild-moderate disease. However, a double-blinded placebo control study found that the level of sputum eosinophils was significantly reduced by simvastatin and inhaled budesonide as compared to patients who received inhaled budesonide only [66]. It has been suggested that this anti-inflammatory effect of simvastatin is through enhancing indoleamine 2,3-dioxygene [66], an important T- cell immunomodulator [67]. These inconclusive clinical findings on the role of statins in asthma could be due to differences in study design and 
treatment duration. Therefore, multicenter clinical trials with larger number of asthma patients with different disease stages and longer treatment period are recommended to critically elucidate the role of statins in asthma.

The safety of statins received a lot of attention during the past years. Myalgia received widely perceived attention as a side effect of statins [68]. Rhabdomyolysis, a rare condition of severe myopathy that causes the release of myoglobin and eventually risk of renal failure, has increased among patients who are taking intensive statin therapy [69]. In 2012, the United States Food and Drug Administration modified the labeling of statins to include a warning regarding the potential negative effect on cognition and glucose level [70]. A recent comprehensive meta-analysis of 25 randomized controlled trials reported on the cognitive effect in 46,836 subjects revealing that statin use is not associated with cognitive decline [71]. In addition, a recent meta-analysis review revealed that statins use is associated with a slight increase in the risk of developing diabetes [72], particularly with more intensive statin therapy [72].

In clinical practice, statins are safe and well tolerated [73] and their benefits outweigh their risk of side effects.

\section{Conclusion}

In vitro and in vivo studies revealed that statins reduce ASMCs proliferation and inflammatory mediators' release. Statins reduce chemokine release and mucus production from airway epithelial cells besides attenuating subepithelial fibrosis and eosinophil recruitment. In acute and chronic allergen-driven animal models of asthma, statins reduce AHR, inflammation and remodeling. The effect of stains in asthma is mediated through their effect on several small $\mathrm{G}$ proteins, inducing cell apoptosis, inhibiting eosinophils adhesion, attenuating fibronectin release and modulating the activation of transcription factors.

Statins are relatively safe and well tolerated; however, more multi-centered clinical trials are needed to evaluate the effect of statins on asthma phenotype of different disease stages.

\section{Disclosure Statement}

There is no financial or other relationship that could lead to conflict of interest.

\section{References}

1 Busse WW, Lemanske RF Jr: Asthma. N Engl J Med 2001;344:350-362.

2 Lemanske RF Jr, Busse WW: 6. Asthma. J Allergy Clin Immunol 2003;111(2 suppl):S502S519.

3 Global Surveillance, Prevention and Control of Chronic Respiratory Diseases: A Comprehensive Approach. World Health Organization, 2007.

4 Masoli M, et al: The global burden of asthma: executive summary of the GINA dissemination committee report. Allergy 2004;59:469-478.

5 Barnes PJ: The cytokine network in asthma and chronic obstructive pulmonary disease. J Clin Invest 2008;118:3546-3556.

6 Watt AP, Schock BC, Ennis M: Neutrophils and eosinophils: clinical implications of their appearance, presence and disappearance in asthma and COPD. Curr Drug Targets Inflamm Allergy 2005;4:415-423.

7 Broadley KJ: Beta-adrenoceptor responses of the airways: for better or worse? Eur J Pharmacol 2006;533:15-27.

8 Dahl R: Systemic side effects of inhaled corticosteroids in patients with asthma. Respir Med 2006;100:1307-1317.

9 Kelly HW, Nelson HS: Potential adverse effects of the inhaled corticosteroids. J Allergy Clin Immunol 2003;112:469-478; quiz 479.

10 Salpeter SR, et al: Meta-analysis: effect of long-acting beta-agonists on severe asthma exacerbations and asthma-related deaths. Ann Intern Med 2006;144:904-912.

11 Currie GP, Lee DK, Lipworth BJ: Long-acting beta2-agonists in asthma: not so SMART? Drug Saf 2006;29:647-656.

12 Papiris S, et al: Clinical review: severe asthma. Crit Care 2002;6:30-44.

13 Bhatnagar D, Soran H, Durrington PN: Hypercholesterolaemia and its management. BMJ 2008;337:a993.

14 Dykstra ML, Cherukuri A, Pierce SK: Floating the raft hypothesis for immune receptors: access to rafts controls receptor signaling and trafficking. Traffic 2001;2:160-166.

15 Anderson HA, Hiltbold EM, Roche PA: Concentration of MHC class II molecules in lipid rafts facilitates antigen presentation. Nat Immunol 2000;1:156-162.

16 Arnaud C, Veillard NR, Mach F: Cholesterolindependent effects of statins in inflammation, immunomodulation and atherosclerosis. Curr Drug Targets Cardiovasc Haematol Disord 2005;5:127-134.

17 Rosenson RS: Non-lipid-lowering effects of statins on atherosclerosis. Curr Cardiol Rep 1999; 1:225-232.

18 Liang PH, Ko TP, Wang AH: Structure, mechanism and function of prenyltransferases. Eur J Biochem 2002;269:3339-3354.

19 Zhang FL, Casey PJ: Protein prenylation: molecular mechanisms and functional conse- quences. Annu Rev Biochem 1996;65:241269.

20 Takeda N, et al: Role of RhoA inactivation in reduced cell proliferation of human airway smooth muscle by simvastatin. Am J Respir Cell Mol Biol 2006;35:722-729.

21 Lambert RK, et al: Functional significance of increased airway smooth muscle in asthma and COPD. J Appl Physiol (1985) 1993;74: 2771-2781.

22 Johnson PR, et al: Airway smooth muscle cell proliferation is increased in asthma. Am J Respir Crit Care Med 2001;164:474-477.

$23 \mathrm{Kamm}$ KE, Stull JT: The function of myosin and myosin light chain kinase phosphorylation in smooth muscle. Annu Rev Pharmacol Toxicol 1985;25:593-620.

24 Amano M, et al: Phosphorylation and activation of myosin by Rho-associated kinase (Rhokinase). J Biol Chem 1996;271:20246-20249.

25 Matsui T, et al: Rho-associated kinase, a novel serine/threonine kinase, as a putative target for small GTP binding protein Rho. EMBO J 1996;15:2208-2216.

26 Koyama M, et al: Phosphorylation of CPI-17, an inhibitory phosphoprotein of smooth muscle myosin phosphatase, by Rho-kinase. FEBS Lett 2000;475:197-200.

27 Kaneko T, et al: Identification of calponin as a novel substrate of Rho-kinase. Biochem Biophys Res Commun 2000;273:110-116. 
28 Winder SJ, Walsh MP: Calponin: thin filament-linked regulation of smooth muscle contraction. Cell Signal 1993;5:677-686.

29 Hershenson MB, et al: Airway smooth muscle in asthma. Annu Rev Pathol 2008;3:523-555.

30 Bentley JK, Hershenson MB: Airway smooth muscle growth in asthma: proliferation, hypertrophy, and migration. Proc Am Thorac Soc 2008;5:89-96.

31 Damera G, Panettieri RA Jr: Does airway smooth muscle express an inflammatory phenotype in asthma? Br J Pharmacol 2011;163: 68-80.

32 Capra V, Rovati GE: Rosuvastatin inhibits human airway smooth muscle cells mitogenic response to eicosanoid contractile agents. Pulm Pharmacol Ther 2014;27:10-16.

33 Lambrecht BN, Hammad H: The airway epithelium in asthma. Nat Med 2012;18:684-692.

34 Bulek K, et al: Epithelium: the interplay between innate and Th2 immunity. Immunol Cell Biol 2010;88:257-268.

35 Aikawa T, et al: Marked goblet cell hyperplasia with mucus accumulation in the airways of patients who died of severe acute asthma attack. Chest 1992;101:916-921.

36 Zeki AA, et al: Differential effects of simvastatin on IL-13-induced cytokine gene expression in primary mouse tracheal epithelial cells. Respir Res 2012;13:38.

37 Yoshisue $\mathrm{H}$, et al: Characterization of ciliated bronchial epithelium 1, a ciliated cell-associated gene induced during mucociliary differentiation. Am J Respir Cell Mol Biol 2004;31: 491-500.

38 Atherton HC, Jones G, Danahay H: IL-13-induced changes in the goblet cell density of human bronchial epithelial cell cultures: MAP kinase and phosphatidylinositol 3-kinase regulation. Am J Physiol Lung Cell Mol Physio 2003;285:L730-L739.

39 Chen YJ, et al: Simvastatin attenuates acrolein-induced mucin production in rats: involvement of the Ras/extracellular signal-regulated kinase pathway. Int Immunopharmacol 2010;10:685-693.

40 Liou CJ, et al: Oral lovastatin attenuates airway inflammation and mucus secretion in ovalbumin-induced murine model of asthma. Allergy Asthma Immunol Res 2014;6:548-557.

$41 \mathrm{Zhu} \mathrm{T}$, et al: Rosuvastatin attenuates mucus secretion in a murine model of chronic asthma by inhibiting the gamma-aminobutyric acid type A receptor. Chin Med J (Engl) 2012; 125:1457-1464.

42 Lu WY, Inman MD: Gamma-aminobutyric acid nurtures allergic asthma. Clin Exp Allergy 2009;39:956-961.

43 Robinson AJ, et al: Fluvastatin and lovastatin inhibit granulocyte macrophage-colony stimulating factor-stimulated human eosinophil adhesion to inter-cellular adhesion molecule-1 under flow conditions. Clin Exp Allergy 2009;39:1866-1874.
44 Walsh GM, et al: Control of eosinophil toxicity in the lung. Curr Drug Targets Inflamm Allergy 2005;4:481-486.

45 Walsh GM: Defective apoptotic cell clearance in asthma and COPD - a new drug target for statins? Trends Pharmacol Sci 2008;29:6-11.

46 Charokopos $\mathrm{N}$, et al: Bronchial asthma, chronic obstructive pulmonary disease and NF-kappaB. Curr Med Chem 2009;16:867883.

47 Hart LA, et al: Activation and localization of transcription factor, nuclear factor-kappaB, in asthma. Am J Respir Crit Care Med 1998; 158(5 pt 1):1585-1592.

48 Fujihara $\mathrm{S}$, et al: Inhibition of nuclear factorkappaB activation un-masks the ability of TNF-alpha to induce human eosinophil apoptosis. Eur J Immunol 2002;32:457-466.

49 Kim DY, et al: Anti-inflammatory mechanism of simvastatin in mouse allergic asthma model. Eur J Pharmacol 2007;557:76-86.

50 McKay A, et al: A novel anti-inflammatory role of simvastatin in a murine model of allergic asthma. J Immunol 2004;172:29032908.

51 Ahmad T, et al: Simvastatin improves epithelial dysfunction and airway hyperresponsiveness: from asymmetric dimethyl-arginine to asthma. Am J Respir Cell Mol Biol 2011;44: 531-539.

52 Zeki AA, et al: Simvastatin inhibits airway hyperreactivity: implications for the mevalonate pathway and beyond. Am J Respir Crit Care Med 2009;180:731-740.

53 Garrington TP, Johnson GL: Organization and regulation of mitogen-activated protein kinase signaling pathways. Curr Opin Cell Biol 1999;11:211-218.

54 Pelaia G, et al: Mitogen-activated protein kinases and asthma. J Cell Physiol 2005;202: 642-653.

55 Imamura $\mathrm{M}$, et al: Pravastatin attenuates allergic airway inflammation by suppressing antigen sensitisation, interleukin 17 production and antigen presentation in the lung. Thorax 2009;64:44-49.

56 Linden A, Dahlen B: Interleukin-17 cytokine signalling in patients with asthma. Eur Respir J 2014;44:1319-1331.

57 Descalzi D, et al: Importance of fibroblastsmyofibroblasts in asthma-induced airway remodeling. Recent Pat Inflamm Allergy Drug Discov 2007; 1:237-241.

58 Hocking DC: Fibronectin matrix deposition and cell contractility: implications for airway remodeling in asthma. Chest 2002;122(6 suppl):275S-278S.

59 Ge Q, et al: Differential deposition of fibronectin by asthmatic bronchial epithelial cells. Am J Physiol Lung Cell Mol Physiol 2015; 309:L1093-L1102.
60 Schaafsma D, et al: Simvastatin inhibits TGF $\beta 1$-induced fibronectin in human airway fibroblasts. Respir Res 2011;12:113.

61 Michalik M, et al: Lovastatin-induced decrease of intracellular cholesterol level attenuates fibroblast-to-myofibroblast transition in bronchial fibroblasts derived from asthmatic patients. Eur J Pharmacol 2013;704: 23-32.

62 Zeki AA, et al: Simvastatin inhibits goblet cell hyperplasia and lung arginase in a mouse model of allergic asthma: a novel treatment for airway remodeling? Transl Res 2010;156: 335-349.

63 Maarsingh H, Zaagsma J, Meurs H: Arginase: a key enzyme in the pathophysiology of allergic asthma opening novel therapeutic perspectives. Br J Pharmacol 2009;158:652664

64 Menzies D, et al: Simvastatin does not exhibit therapeutic anti-inflammatory effects in asthma. J Allergy Clin Immunol 2007;119:328335

65 Moini A, Azimi G, Farivar A: Evaluation of atorvastatin for the treatment of patients with asthma: a double-blind randomized clinical trial. Allergy Asthma Immunol Res 2012;4: 290-294.

66 Maneechotesuwan K, et al: Statins enhance the anti-inflammatory effects of inhaled corticosteroids in asthmatic patients through increased induction of indoleamine 2, 3-dioxygenase. J Allergy Clin Immunol 2010;126: 754-762.e1

67 Le AV, Broide DH: Indoleamine-2,3-dioxygenase modulation of allergic immune responses. Curr Allergy Asthma Rep 2006;6: 27-31.

68 Rosenson RS, et al: An assessment by the statin muscle safety task force: 2014 update. J Clin Lipidol 2014;8(3 suppl):S58-S71.

69 Study of the Effectiveness of Additional Reductions in Cholesterol and Homocysteine (SEARCH) Collaborative Group, Armitage J, et al: Intensive lowering of LDL cholesterol with $80 \mathrm{mg}$ versus $20 \mathrm{mg}$ simvastatin daily in 12,064 survivors of myocardial infarction: a double-blind randomised trial. Lancet 2010; 376:1658-1669.

70 US Food and Drug Administration: FDA Drug Safety Communication: Important Safety Label Changes to Cholesterol-Lowering Statin Drugs, 2012.

71 Ott BR, et al: Do statins impair cognition? A systematic review and meta-analysis of randomized controlled trials. J Gen Intern Med 2015;30:348-358.

72 Thakker D, et al: Statin use and the risk of developing diabetes: a network meta-analysis. Pharmacoepidemiol Drug Saf 2016, Epub ahead of print.

73 Armitage J: The safety of statins in clinical practice. Lancet 2007;370:1781-1790. 